
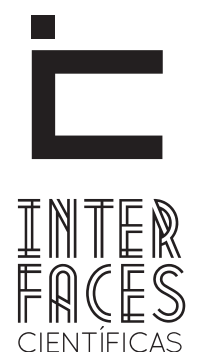

EDUCAÇÃO

ISSN IMPRESSO 2316-333X

E-ISSN 2316-3828

DOI 10.17564/2316-3828.2016v4n2p11-22

\title{
PRÁTICAS DE ENSINO DE LEITURA E ESCRITA DE PROFESSORAS ALFABETIZADORAS EM PROCESSO DE FORMAÇÃO
}

Alexsandro da Silva ${ }^{1}$

July Rianna de Melo $^{3}$

Estephane Priscilla dos Santos Mendes²

\section{RESUMO}

Este estudo visou a analisar as práticas de ensino de leitura e escrita de duas professoras alfabetizadoras em processo de formação continuada. Como procedimentos metodológicos, adotamos a observação participante e a entrevista semiestruturada e, para analisar os dados, recorremos à análise temática de conteúdo. Os resultados evidenciaram um movimento entre as propostas do curso de formação e as ações desenvolvi-

das pelas professoras em sala de aula e não uma mera repetição das orientações a que elas tiveram acesso.

\section{PALAVRAS-CHAVE}

Alfabetização. Formação Continuada. Leitura e Escrita. 


\section{ABSTRACT}

This study aimed to analyze the teaching practices of reading and writing of two literacy's teachers in continuing education process. As methodological procedures, we adopted the participant observation and semi-structured interview and, to analyze the data, we used the thematic content analysis. The results showed a movement among the proposals of the training course and the actions taken by the teachers in the classroom and not a mere repetition of the guidelines they had access.

\section{KEYWORDS}

literacy. Continuing education. Reading and writing.

\section{RESUMEN}

Este estudio tuvo como objetivo analizar la enseñanza de las prácticas de lectura y escritura de dos alfabetizadores en continuo proceso de educación. Como procedimientos metodológicos, adoptamos la observación participante y la entrevista semiestructurada y, para analizar los datos, se utilizó el análisis de contenido temático. Los resultados mostraron un movimiento entre las propuestas del curso de formación y las acciones desarrolladas por los profesores en el aula y no una mera repetición de las directrices que tenían acceso.

\section{PALABRAS CLAVE}

Alfabetización. La educación continua. La lectura y la escritura. 


\section{INTRODUÇ̄̃O}

A partir, principalmente, dos anos 1980 do século $\mathrm{XX}$ os métodos tradicionais de ensino de leitura e escrita e as cartilhas que os concretizavam tornaram-se, no contexto brasileiro, alvo de muitas críticas. Tais críticas, impulsionadas, sobretudo, por mudanças conceituais no campo da alfabetização, oriundas especialmente da teoria da Psicogênese da Escrita (FERREIRO; TEBEROSKY, 1999), deslocaram a discussão sobre o "como se ensina" para o "como se aprende" (MORTATTI, 2000; SOARES, 2004).

Nessa teoria, a aprendizagem da escrita alfabética é concebida como uma construção conceitual, isto é, como um processo de compreensão de um sistema de representação (notação) dos segmentos sonoros das palavras e não como a aquisição de um código de transcrição da fala, na qual estariam envolvidos aspectos meramente perceptivo-motores, que era a concepção subjacente aos antigos métodos de alfabetização.

Na década 1990, os estudos sobre letramento, entendido como o desenvolvimento de comportamentos e habilidades de uso competente da leitura e da escrita em práticas sociais diversas (SOARES, 1998), também começaram a se difundir com maior intensidade em nosso país. Apoiando-se nesse conceito, Soares (1998) propõe que o ideal seria alfabetizar letrando, isto é, ensinar a ler e a escrever no contexto das práticas sociais de leitura e escrita. Em outras palavras, tanto as atividades de reflexão sobre o sistema escrita alfabética (SEA) e suas convenções, quanto as práticas sociais de leitura e escrita deveriam ser contempladas em sala de aula, mesmo antes de a criança ter aprendido a ler e escrever convencionalmente.

Nesse cenário de mudanças conceituais, especialmente a partir do início do século XXI, diversos programas governamentais de formação continuada de professores alfabetizadores têm sido ofertados às redes públicas de ensino do país. São exemplos o
Programa de Formação de Professores Alfabetizadores (PROFA), o Pró-Letramento e, mais recentemente, o curso de formação de professores alfabetizadores oferecido no âmbito do Pacto Nacional pela Alfabetização na Idade Certa (PNAIC).

O PNAIC, que interessa especialmente a este trabalho, foi lançado pelo Governo Federal em 2012 e constitui um compromisso formal dos governos federal, estaduais e municipais de assegurar que todas as crianças estejam alfabetizadas até os oito anos de idade, isto é, que concluam o $3^{\circ}$ ano do ensino fundamental não apenas tendo compreendido o sistema de escrita alfabética e dominando as correspondências entre grafemas e fonemas, mas lendo e produzindo textos com autonomia.

As ações do PNAIC compreendem quatro eixos de atuação: formação continuada de professores alfabetizadores e de orientadores de estudo; materiais didáticos, obras literárias e de apoio pedagógico, jogos e tecnologias educacionais; avaliações sistemáticas; gestão, mobilização e controle social. Uma das principais desse Programa é a formação continuada de professores alfabetizadores, a qual inclui curso presencial, ministrado por orientadores de estudo formados por universidades públicas.

Nesse contexto, surgem questões que consideramos relevante investigar mais detidamente, as quais constituem objeto de análise deste artigo: como os professores têm compreendido e se apropriado das orientações desse curso de formação de continuada? Como eles têm materializado, em sala de aula, tais orientações? Como as apropriações dessas orientações relacionam-se com mudanças nas práticas de ensino?

Durante muito tempo, acreditou-se que os professores seriam (ou deveriam ser) repetidores, em suas salas de aula, das orientações a que tivessem acesso nos cursos de formação inicial ou continuada. Contrariando essa perspectiva, compreendemos, atualmente, que eles são sujeitos inventivos e produtivos e, por 
isso mesmo, não recebem passivamente aquilo a que têm acesso nas diferentes experiências formativas das quais participam, mas, antes, reelaboram, recriam e reinventam as "inovações" em sua ação cotidiana.

Como esclarece Certeau (2012, p. 100), os homens não são meros consumidores das produções culturais, pois se apropriam delas, reinventando-as em seu cotidiano, por meio de "táticas de consumo". Segundo Sarti (2008), nessa perspectiva, "o consumo cultural revela-se como um espaço de produção de sentidos, uma produção silenciosa que possibilita que os sujeitos, por meio de seus afazeres mais ordinários, não estejam destinados à passividade e à reprodução" (SARTI, 2008, p. 49).

Desse modo, apoiando-nos em Chartier (2007) e Tardif (2001), podemos dizer que as "inovações" são avaliadas e validadas ou não pelos professores por meio de critérios pragmáticos e não teóricos e são incorporadas apenas quando contribuem, de alguma maneira, para organização do trabalho pedagógico. Caso contrário, são adaptadas ou mesmo descartadas, principalmente quando parecem inúteis ou sem relação com a realidade vivida e representam um aumento da carga de trabalho. Por isso, é preciso distinguir "coerência teórica" ou "racionalidade científica" de "coerência pragmática" ou "racionalidade docente".

Considerando tais perspectivas, apresentaremos, neste artigo, resultados de uma pesquisa que desenvolvemos com o objetivo de analisar as práticas de ensino de leitura e escrita de professoras alfabetizadoras em processo de formação continuada, no âmbito do Pacto Nacional pela Alfabetização na Idade Certa.

\section{SOBRE AS OPÇÕES METODOLÓGICAS DA PESQUISA}

Considerando a natureza do nosso objeto de estudo, adotamos uma abordagem qualitativa de pesquisa, que, de acordo com Minayo (2011), ocupa-se do universo de significados, motivos, aspirações, crenças, valores e atitudes. No entanto, por entendermos, assim como essa autora, que não existe dicotomia entre qualidade e quantidade, recorremos, também, quando necessário, a dados quantitativos.

Participaram da pesquisa duas professoras que atuavam, em 2013, no $1^{\circ}$ ano do ensino fundamental em escolas públicas municipais da região agreste do estado de Pernambuco e que estavam, à época, participando do curso de formação continuada de professores alfabetizadores ofertado no âmbito do PNAIC. Para preservar o anonimato das docentes, referir-nos-emos a elas usando os termos "Professora A" e "Professora B".

No quadro a seguir, apresentamos algumas informações relativas à formação e à experiência profissional das docentes.

Quadro 1 - Formação e tempo de docência das professoras

\begin{tabular}{|c|c|l|c|}
\hline Professora & $\begin{array}{c}\text { Ensino Médio } \\
\text { (curso e ano de conclusão) }\end{array}$ & $\begin{array}{c}\text { Ensino Superior } \\
\text { (curso e ano de conclusão) }\end{array}$ & $\begin{array}{c}\text { Tempo de atuação } \\
\text { como alfabetizadora }\end{array}$ \\
\hline A & Magistério (1985) & Licenciatura em História (1989) & 16 anos \\
\hline B & Estudos Gerais (2004) & $\begin{array}{l}\text { Licenciatura em Pedagogia (2008) } \\
\text { Especialização em Gestão Escolar (em } \\
\text { andamento) }\end{array}$ & 5 anos \\
\hline
\end{tabular}

Fonte: Acervo da pesquisa 
Os dados do Quadro 1 evidenciam que, quanto à formação profissional, a professora A possui curso de Magistério, concluído no ano 1985, e licenciatura em História, cujo ano de conclusão foi em 1989. Já professora B é licenciada em Pedagogia desde o ano de 2008 e, à época da pesquisa, cursava Especialização em Gestão Escolar. Com relação ao tempo de atuação como alfabetizadora, percebemos que a professora $A$ era mais experiente que a professora $B$, que atuava há apenas cinco anos como docente.

Para atender ao objetivo da pesquisa, que consistiu em analisar as práticas de ensino de leitura e escrita de professoras em processo de formação continuada, utilizamos os seguintes procedimentos metodológicos: observação em sala de aula e entrevista semiestruturada.

As observações foram realizadas durante um semestre letivo, sendo as aulas das docentes observadas em dez (professora A) e oito dias (professora B) letivos. $O$ registro dos dados foi feito com o auxílio de dois instrumentos: o diário de campo e a gravação de áudio. Já a entrevista semiestruturada, realizada com apoio de gravação em áudio e de um roteiro previamente elaborado, ocorreu ao longo e ao término das observações, a fim de esclarecermos alguns aspectos sobre as práticas de ensino de leitura e escrita observadas e de mapearmos a formação e a experiência profissional das docentes.

Os dados obtidos por meio dos procedimentos metodológicos explicitados foram tratados utilizando a análise de conteúdo (BARDIN, 1979). A análise de conteúdo foi desenvolvida por temas (análise temática categorial) e contemplou as seguintes etapas: pré-análise, análise do material (codificação e categorização da informação) e tratamento dos resultados, inferência e interpretação.

\section{PRÁTICAS DE ENSINO DE LEITURA E ESCRITA DAS PROFESSORAS ALFABETIZADORAS: DA FORMAÇÃO CONTINUADA À SALA DE AULA}

\subsection{ANÁLISE DAS PRÁTICAS DA PROFESSORA ALFABETIZADORA A}

Ao analisar as práticas de ensino de leitura e escrita da professora A, percebemos que ela usava antigas cartilhas de alfabetização, sob a forma de fichas de leitura, o que se distanciava das orientações que se tornaram hegemônicas, no campo do ensino da leitura e da escrita, desde a década 1980, e que se encontravam presentes, de certo modo, no curso de formação continuada do qual a alfabetizadora participava.

No cenário educacional brasileiro, presenciamos, a partir daquela década, um intenso discurso contrário ao uso das cartilhas, uma vez que elas reduziam o ler e o escrever ao domínio de uma técnica, que consistia em converter os sinais gráficos em sinais sonoros e vice-versa, sem reflexão, por parte da criança, sobre as relações entre as partes sonoras e escritas das palavras.

O depoimento apresentado a seguir permitiu-nos perceber que as fichas de leitura, que foram usadas em metade das aulas observadas (5/10), eram tidas, pela professora, como um material importante para a aprendizagem da leitura, pois considerava que o seu uso frequente permitiria aos alunos tornarem-se bons leitores:

\footnotetext{
Eu fazia a leitura de toda consoante que eu dava. Eu acho que a ficha de leitura funciona demais, demais até. E se você começar desde o começo do ano até o final, dificilmente fica algum aluno sem saber ler. Se fizer a ficha de leitura e ficar lendo só uma vez na semana, também não vai fluir muito não. Tem que ser todo dia.
} 
A utilização dessas fichas ocorria sempre no início das aulas e obedecia aos mesmos procedimentos: em um primeiro momento, eram chamados os alunos do terceiro nível ${ }^{1}$ para realizar a leitura em duplas e/ou em grupos. A professora indicava a leitura com o dedo e pedia para que as crianças lessem sempre na mesma ordem: letra, família silábica, palavras e texto cartilhado. Depois, repetia, sistematicamente, os mesmos procedimentos com os/as alunos/as do segundo nível. A seguir, apresentamos um exemplo de uma das fichas de leitura utilizada pela professora:

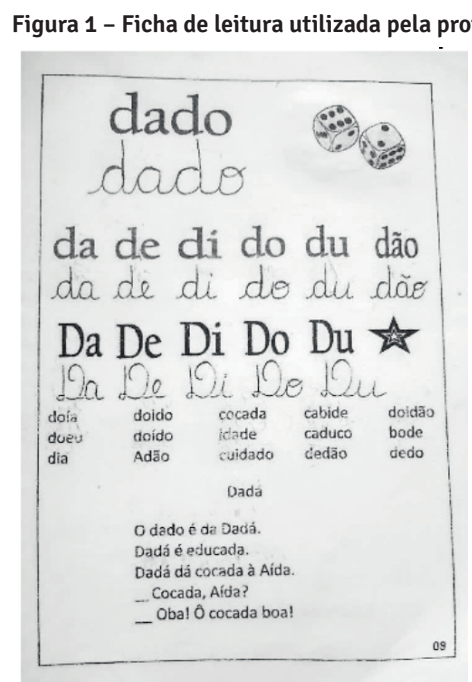

Fonte: Acervo da pesquisa.

É relevante ressaltar que a ênfase nas atividades de leitura como decodificação poderia, em certa medida, estar relacionada à identificação da professora alfabetizadora com alguns programas do qual participou, entre eles o Se Liga, que têm uma proposta pautada no método silábico de alfabetização (DOURADO, 2010). É nessa linha que interpretamos um dos depoimentos da professora:

1. As crianças eram separadas, pela professora, em três níveis, conforme a fluência que tinham em leitura: o primeiro era constituído pelas que já liam fluentemente; o segundo, pelas que liam sílabas, palavras e textos curtos; 0 terceiro, pelas que liam apenas sílabas e algumas palavras com muita dificuldade (informações fornecidas pela professora).
Participei dos programas Se Liga e Acelera e, para mim, foi um dos melhores que teve. Utilizo coisas do Se liga, porque tudo que eu faço hoje e essas leituras que eu vivo fazendo direto na sala foi tudo do Programa. Era muita produção de texto. Tudo que eu fazia no Se Liga eu ainda continuo fazendo, mesmo com livros diferentes e tudo mais... Assim, até mesmo depois do Pacto, eu continuei com as coisas de primeiro.

À luz desse depoimento, podemos concluir que a alfabetizadora mantinha práticas de ensino vivenciadas anteriormente, ainda que elas não se coadunassem às orientações e às propostas do curso de formação do qual participava. Diante disso, reconhecemos que os diferentes saberes-fazeres que integravam as práticas dessa professora, os quais tinham sido construídos ao longo de seu processo de formação e de atuação e validados pela própria experiência, orientavam suas escolhas didáticas e pedagógicas. Duran (2007, p. 125-126), ao analisar o depoimento de uma alfabetizadora em processo de formação que disse manter "a cartilha atrás da porta", explicitou que isso,

[...] pode significar também uma "ação calculada", uma tática, uma singularidade no 'uso' de regras e produtos impostos e que pode levar às possibilidades múltiplas de compreensão das práticas alfabetizadoras, às possibilidades de efetivamente se considerar os modos como os professores incorporaram, transformaram ou resistiram às orientações impostas por uma ordem social dominante.

Embora demonstrasse vincular-se a perspectivas mais tradicionais de alfabetização, percebemos, por outro lado, que algumas das práticas e dos materiais didáticos utilizados pela professora, como uso das obras complementares e dos jogos distribuídos pelo Ministério da Educação, aproximavam-se, de certo modo, da proposta de alfabetizar letrando preconizada pelo curso de formação continuada. Isso parecia evidenciar aquilo que Chartier (2007) denominou de "coerência pragmática" e não uma mera incompatibilidade de perspectivas teóricas. Eis um dos depoimentos da professora: 
Na leitura, [a minha prática] mudou por conta dos livros [das obras complementares], que são muitos que vêm na caixa. A maioria já leu mais da metade dos livros. Então, [a minha prática] mudou nos livros, né? E também os jogos, né? Que envolve muitas disciplinas. Tem a matemática, tem a escrita, tem a leitura. Mudou, então, nos livros e nos jogos.

Assim, durante as observações em sala de aula, percebemos que um dos recursos mais utilizados pela professora para as atividades de leitura eram os livros do acervo das obras complementares, materiais cujo uso é sistematicamente recomendado nos cadernos de formação do PNAIC e que contemplam, entre outros, livros de divulgação do saber científico/obras didáticas, biografias, livros instrucionais, livros de cantigas, parlendas, trava-línguas e histórias em quadrinhos.

A leitura das obras complementares era realizada, sobretudo, pelas crianças que já se encontravam no "primeiro nível", isto é, aquelas que já liam convencionalmente. Elas selecionavam os livros para ler, enquanto a professora acompanhava a leitura das outras crianças com as fichas anteriormente referidas. Não havia, nesses momentos, qualquer intervenção quanto à condução da situação de leitura. Essa estratégia era utilizada, ao que parece, principalmente, para que os alunos estivessem ocupados, enquanto a professora acompanhava a leitura dos outros. Já os discentes do segundo e terceiro níveis de leitura só tinham acesso aos livros das obras complementares depois de terem lido/decodificado a ficha.

As obras complementares, também, eram utilizadas em outras situações pela professora. Nessas propostas de ensino de leitura, a alfabetizadora selecionava uma das crianças que já sabia ler com fluência para que fizesse a leitura do livro em voz alta e solicitava que essa criança prestasse atenção a aspectos importantes do livro (autoria, edição, ilustração, título do livro etc.), enquanto os demais acompanhavam.

Além do uso das obras complementares em sala de aula, a professora também promovia o empréstimo desses livros, que se destinava, a princípio, apenas às crianças que já sabiam ler convencionalmente. No entanto, no decorrer dessa proposta, a professora percebeu que era necessário oportunizar aos outros alunos o convívio com a cultura escrita. No caso dos alunos que ainda não liam convencionalmente, era proposto, segundo a docente, o reconto do livro a partir das ilustrações. Durante as observações, registramos apenas uma ocasião em que houve o empréstimo dos livros para todos os alunos, mas não presenciamos nenhuma atividade de reconto.

Evidenciamos, também, situações de leitura em que os livros escolhidos pela professora não faziam parte do acervo das obras complementares ou tratavam-se de livros trazidos pelos próprios alunos. Em uma das aulas, o livro utilizado pela docente havia sido sugerido pela coordenadora pedagógica do PNAIC na escola, que costumava acompanhar e fotografar as aulas.

Conforme dissemos anteriormente, a professora também sinalizou a presença de jogos de alfabetização em suas práticas, cujo uso foi observado por nós em uma das aulas. Ressaltamos que, também nesse caso, os cadernos do curso de formação incentivavam o uso desse recurso didático distribuídos pelo MEC, os quais já eram utilizados pela professora, conforme podemos observar no depoimento a seguir:

\begin{abstract}
Cada jogo tem um objetivo e o meu maior objetivo é a leitura, até nas propostas de atividades de matemática. 0 que achei mais difícil é o uso do jogo para aqueles que não sabem ler, mas mesmo assim participam perguntando, lendo as imagens e prestando atenção na figura. No ano passado eu também usava os jogos do CEEL, que na escola já tinha. E era bem bom, que assim tem as rimas e tem muita coisa assim diferente que eu já usava.
\end{abstract}

Na subseção a seguir, dando continuidade à análise, discutiremos as práticas de ensino de leitura e escrita desenvolvidas pela professora B, que, assim, como a professora A, participava de curso de formação continuada do PNAIC, conforme dissemos anteriormente. 


\subsection{ANÁLISE DAS PRÁTICAS DA PROFESSORA ALFABETIZADORA B}

Ao analisar as práticas de ensino de leitura e escrita da professora $B$, percebemos que foram realizadas, de modo geral, poucas atividades relativas ao ensino SEA em cada aula observada, conforme pode- mos observar no Quadro 2, a seguir. É importante registrar também que, em apenas algumas aulas, tais atividades foram realizadas mais sistematicamente, pois, nas demais, elas ocorreriam de maneira assistemática, em meio a outras atividades. Além disso, em três das oito aulas não foram desenvolvidas atividades dessa natureza.

\begin{tabular}{|c|c|c|c|c|c|c|c|c|}
\hline \multirow{2}{*}{ Atividade } & \multicolumn{8}{|c|}{ Aulas } \\
\hline & $1^{a}$ & $2^{\mathbf{a}}$ & $3^{a}$ & $4^{a}$ & $5^{a}$ & $6^{a}$ & $7^{a}$ & $8^{a}$ \\
\hline Separação de sílabas (por escrito) & $x$ & & & & & & & $x$ \\
\hline $\begin{array}{l}\text { Associação de figuras às palavras } \\
\text { correspondentes }\end{array}$ & $x$ & & & & & & & $x$ \\
\hline Escrita dos nomes de figuras & $x$ & & & & & & & \\
\hline $\begin{array}{l}\text { Substituição de letras em palavras para } \\
\text { formação de outras palavras }\end{array}$ & $x$ & & $x$ & & & & & \\
\hline Exploração de letra inicial de palavras & $x$ & & & & & & & \\
\hline $\begin{array}{l}\text { Escrita de texto conhecido de memória pela } \\
\text { criança }\end{array}$ & & & & & $x$ & & & \\
\hline Contagem de letras & & & & & $x$ & & & \\
\hline Cópia do alfabeto & & & & & $x$ & & & \\
\hline Leitura de palavras & & & & & & & $x$ & \\
\hline
\end{tabular}

Fonte: Acervo da pesquisa.

A professora $B$, em um de seus depoimentos, afirmou que o curso de formação do PNAIC estava fazendo-a "abandonar o tradicionalismo de trabalhar com, por exemplo, padrões silábicos ou o estudo isolado das letras para alfabetizá-los a partir de textos de usos reais". Diante desse depoimento, consideramos que o contato, no processo formativo, com diferentes discussões sobre alfabetização pode ter tido alguma relação com essa ausência de ensino sistemático, embora essa não fosse a proposta do referido curso de formação, que defendia, ao contrário, o ensino regular e contínuo da escrita alfabética. Desse modo, parece estarmos diante de uma apropriação feita professora ou por seu(a) formador(a) da proposta do curso de formação.

No entanto, cabe ressaltar também que, à época em que as observações foram realizadas, a professora 
estava estudando, no curso de formação, os cadernos referentes à ludicidade e aos gêneros textuais, o que pode ter influenciado as aulas observadas, tendo em vista que fazia parte do processo formativo que os docentes desenvolvessem, em sala de aula, atividades discutidas na formação ou elaboradas a partir dela.

Outro aspecto observado nas práticas de alfabetização desenvolvidas pela professora $B$ relacionou-se à exploração de diversos textos e gêneros no processo de alfabetização. Quando perguntamos à docente qual o caderno e/ou temática abordado na formação que mais estava contribuindo para as suas práticas em sala de aula, ela respondeu o seguinte: "O trabalho com gêneros textuais, pois acredito que esse trabalho de apropriação da escrita a partir dos textos facilita o processo de alfabetização".

Nas aulas observadas, percebemos o uso de gêneros textuais diferentes, além da utilização do acervo de obras complementares, conforme podemos observar no quadro apresentando seguir. No caso da obra $O$ Mundinho Azul, por exemplo, a docente abordou um conteúdo da área de ciências naturais, explorando a capa do livro (o autor e outros elementos que constituem a obra) e as imagens nele contidas, assim como algumas estratégias de leitura. Já no caso do livro De Avestruz a Zebra, a professora explorou a letra inicial dos nomes de animais, estabelecendo relações com outro livro já lido (ABC dos animais).

Quadro 3 - Textos e gêneros explorados nas aulas observadas

\begin{tabular}{|l|c|c|c|c|c|c|c|c|}
\hline \multirow{2}{*}{\multicolumn{1}{c|}{ Textos e gêneros }} & \multicolumn{7}{c|}{ Aulas } \\
\cline { 2 - 10 } & $\mathbf{1}^{\mathbf{a}}$ & $\mathbf{2}^{\mathbf{a}}$ & $\mathbf{3}^{\mathbf{a}}$ & $\mathbf{4}^{\mathbf{a}}$ & $\mathbf{5}$ & $\mathbf{6}$ & $\mathbf{7}^{\mathbf{a}}$ & $\mathbf{8}^{\mathbf{a}}$ \\
\hline De avestruz a Zebra (obra complementar) & $\mathrm{X}$ & & & & & & & \\
\hline Bolo Bom Bocado (receita culinária) & & $\mathrm{X}$ & & & & & & \\
\hline Os 3 Porquinhos (conto) & & & $\mathrm{X}$ & & & & & \\
\hline O Mundinho Azul (obra complementar) & & & & $\mathrm{X}$ & & & & \\
\hline O Sapo Não Lava o Pé (música) & & & & & $X$ & $X$ & & \\
\hline
\end{tabular}

Fonte: Acervo da pesquisa.

A professora também ressaltou o lúdico como outra temática abordada na formação que considerou importante para as suas práticas. Segundo a alfabetizadora, "[...] trabalhar com jogos e brincadeiras e outras atividades lúdicas desperta a atenção das crianças e contribui bastante para a construção do conhecimento". No depoimento a seguir, ela relatou as atividades realizadas em uma das aulas, que consistiu em dois jogos, o primeiro envolvendo uma lista de palavras com S, no qual a criança que não conseguisse dizer alguma palavra com essa letra em cada rodada saía do jogo, e o segundo, uma pescaria, na qual os alunos deveriam ler a palavra que estava colada no peixe que pescasse:

A primeira atividade me deixou bem surpresa e satisfeita. Poucas crianças não conseguiram dizer nenhuma palavra, e outras disseram até palavras que nem imaginei que elas diriam, que nem eu tinha pensado. Então, gostei bastante. E com relação à pescaria, o objetivo era a leitura de palavras, porque, assim, é uma forma diferente de ver com eles a questão da leitura. Porque quando a gente chama para o birô ou pede pra ler no quadro, eles ficam logo com medo, tem uns que 
chega ficam tensos, e assim não, eles achando que é uma brincadeira, ficam mais relaxados e descontraídos. Aí é bem melhor o desempenho deles.

A título de considerações finais, apresentaremos, a seguir, algumas conclusões que pudemos extrair sobre as práticas de ensino de leitura e escrita das duas professoras alfabetizadoras que se encontravam em processo de formação continuada.

\section{CONSIDERAÇÕES FINAIS}

Os resultados apresentados anteriormente permitiram concluir que as práticas de ensino de leitura e escrita das professoras participantes da pesquisa aproximavam-se, em certos momentos, das orientações do PNAIC e, em outros, distanciavam-se, revelando um movimento entre as propostas de formação e as ações desenvolvidas em sala de aula.

No caso da professora $A$, percebemos que ela mantinha práticas de ensino vivenciadas anteriormente, como uso de cartilhas, sob a forma de fichas de leitura, pois as considerava úteis no processo de alfabetização. Por outro lado, parecia ter incorporado algumas práticas que se coadunavam à formação recebida, como o uso das obras complementares e o trabalho com os gêneros textuais. Em outras palavras, não se reconhecendo como repetidora em sala de aula dessa formação, ela utilizava outros materiais e desenvolvia outras práticas que the pareciam mais adequadas para ensinar a ler e escrever, ainda que, muitas vezes, estivesse subjacente a essas propostas uma concepção tradicional de ensino da língua.

No que se refere à professora $B$, os resultados permitiram perceber que ela também tinha se apropriado de alguns elementos da formação, dentre eles destacaram-se o trabalho com gêneros textuais e a ludicidade. Por outro lado, outro aspecto observado nas práticas de alfabetização dessa professora relacionou-se ao ensino pouco sistemático do SEA. Podemos concluir, portanto, que as práticas de ensino da leitura e da escrita da professora caracterizavam-se pela ênfase nas atividades que contemplavam a dimensão do letramento e pela ausência de maior sistematicidade do ensino do SEA, o que parece ter sido resultado de uma apropriação das orientações do curso de formação.

Em suma, as práticas de ensino de leitura e escrita desenvolvidas pelas professoras evidenciam que ações docentes não constituem uma mera repetição daquilo a que elas tiveram acesso no curso de formação continuada, mas, sim, resultado de um processo complexo de (re)construção. Nesse processo, reconstroem e adequam ao seu trabalho cotidiano os conhecimentos e as orientações a que têm acesso, mantendo, apenas, aqueles que podem ter um "valor de uso" nas práticas (CHARTIER, 2007).

\section{REFERÊNCIAS}

\section{BARDIN, Laurence. Análise de conteúdo. Lisboa: 70, 1979.}

\author{
CERTEAU, Michel de. A invenção do cotidiano. \\ 19.ed. Tradução Ephrain Ferreira Alves. \\ Petrópolis: Vozes, 2012.
}

\section{CHARTIER, Anne-Marie. Práticas de leitura e}

escrita: historia e atualidade. Belo Horizonte: CEALE: Autentica, 2007.

\section{DOURADO, Viviane Carmem de Arruda. 0}

\section{atendimento a crianças com dificuldades de} aprendizagem: práticas de professores e material didático do programa “Se Liga”. 2010. Dissertação (Mestrado em Educação) - Universidade Federal de Pernambuco, Recife, 2010.

DURAN, Marília C. G. Maneiras de pensar o cotidiano com Michel de Certeau. Diálogo Educacional, v. 7, n. 22, Curitiba, set./dez. 2007. p.115-128. 
FERREIRO, Emilia; TEBEROSKY, Ana. Psicogênese da língua escrita. Porto Alegre: Artes Médicas, 1985.

MINAYO, Maria Cecília S. O desafio da pesquisa social. In: MINAYO, M. C. S. (Org.). Pesquisa social: teoria, método e criatividade. 30.ed. Petrópolis-RJ: Vozes, 2011.

MORAIS, Artur Gomes de. Sistema de escrita alfabética. São Paulo: Melhoramentos, 2012.

MORTATTI, Maria do Rosário Longo. Os sentidos da alfabetização (São Paulo: 1876-1994). São Paulo: UNESP; CONPED, 2000.
SARTI, Flávia Medeiros. O professor e as mil maneiras de fazer no cotidiano escolar. Educação: teoria e prática, v.18, n.30, Rio Claro-SP, jan./jun. 2008. p.47-65.

SOARES, Magda. Letramento: um tema em três gêneros. Belo Horizonte: Autêntica, 1998.

SOARES, Magda. Letramento e alfabetização: as muitas facetas. Revista Brasileira de Educação, n. 25, Rio de Janeiro, jan./abr. 2004. p.5-17.

TARDIF, Maurice. Saberes docentes e formação profissional. Petrópolis: Vozes, 2002. 
Recebido em: 4 de dezembro de 2015 Avaliado em: 15 de janeiro de 2016 Aceito em: 29 de janeiro de 2016
1. Doutor em Educação e professor do Núcleo de Formação Docente e do Programa de Pós-Graduação em Educação Contemporânea - Universidade Federal de Pernambuco (UFPE). E-mail: alexs-silva@uol.com.br

2. Mestranda em Educação Contemporânea pela Universidade Federal de Pernambuco (UFPE) e bolsista da CAPES. E-mail: estephane92@hotmail.com

3. Mestranda em Educação Contemporânea pela Universidade Federal de Pernambuco (UFPE) e bolsista da FACEPE. E-mail: julynha_melo@hotmail.com 